\title{
Study on adsorption behavior and separation efficiency of naturally occurring clay for some elements by batch experiments
}

\author{
Abd El Hakim Taha Kandila,*, Ebtssam Ahamed Saadb, \\ Ayman Ahmed Abdel Aziz ${ }^{\mathrm{b}}$ and Amir Ezzat Aboelhasan ${ }^{\mathrm{b}}$ \\ a Department of Chemistry, Faculty of Science, Helwan University, Helwan, 11790, Egypt \\ b Department of Chemistry, Faculty of Science, Ain Shams University, Cairo, 11566, Egypt \\ *Corresponding author at: Department of Chemistry, Faculty of Science, Helwan University, Helwan, 11790, Egypt. \\ Tel.: +20.10.06607757; fax: +20.2.25552468. E-mail address: abdelhakimkandil@yahoo.com (A.E.H.T. Kandil).
}

\section{ARTICLE INFORMATION}

Received: 01 December 2011

Received in revised form: 29 December 2011

Accepted: 13 January 2012

Online: 31 March 2012

\section{KEYWORDS}

\section{Adsorption}

Natural clay

Separation factor

Radioactive waste

Batch experiments

Thermodynamic parameters

\begin{abstract}
This paper describes the versatile nature of clay that was obtained from Suez Gulf, Suez city, Egypt, as a new low cost natural resource which is non toxic to ecosystem and highly effective adsorbent material. The properties of the natural clay and its significance in removing Th(IV) and $\mathrm{Ce}(\mathrm{IV})$ as a representative of tetravalent actinides and lanthanides, respectively, La(III) as a representative of trivalent lanthanides as well as homologues of americium and $\mathrm{Sr}$ (II) as one of the fission products, in aqueous solutions have been studied, in order to consider its application for nuclear waste treatment. Batch experiments have been carried out to determine the effect of various factors such as initial metal ion concentration, clay dose, $\mathrm{pH}$, contact time, and temperature on the adsorption process. The results have dictated that, the adsorption efficiency of the natural clay was significantly high at $\mathrm{pH}=4$. Maximum metal ion uptake capacity of clay has been obtained from batch studies was 99.24, 98.21, 77.76 and $57.94 \%$ for Th(IV), Ce(IV), La(III) and Sr(II), respectively. The thermodynamic parameters $\left(\Delta H^{\circ}, \Delta S^{\circ}\right.$ and $\left.\Delta G^{\circ}\right)$ have been calculated from the temperature dependent adsorption isotherms. Furthermore, separation factors $(\alpha)$ have been calculated in order to separate these elements from each other at $\mathrm{pH}=4$.
\end{abstract}

\section{Introduction}

The long-lived radionuclides in radioactive waste have been considered to be dangerous pollutants, and their migration with ground water is strongly affected by adsorption on the geologic materials. The presence of radionuclides and toxic metals in wastes is of major environmental concern. Such wastes arise from technologies producing nuclear fuels, and from laboratories working with radioactive materials [1]. In all cases radioactive waste need to be managed responsibly to ensure public safety, protection of the environment, and security from malicious intervention now and in the future. This need would remain even if it were to be decided tomorrow to discontinue nuclear power programs or other uses of radioactive materials. The toxic nature of these radionuclides, even at trace levels, has been a public health problem for many years [2]. Among the discernible factors influencing the migration of radionuclides in natural environments, adsorption is one of the more important, so the adsorption procedures are introduced as a favorable way for the remediation of aquatic waste because of its efficacy, practicality and economical feasibility, as depending on the used adsorbents. Adsorption methodologies have been proposed as an alternative process for resolving such problems [3-8]. Adsorption of radionuclides on clay minerals has been studied intensively in the last decades [9-21].

Clays are hydrous aluminosilicates broadly defined as those minerals that make up the colloid fractions of soils, sediments, rocks and water and may be composed of mixture of fine grained clay mineral sand clay-sized crystals of the minerals such as quartz, carbonate and mineral oxides [22].

The adsorption capabilities of clay results from a net negative charge on the structure fine grain silicate minerals, giving clay the ability to attract and hold cations [23]. This negative charge is neutralized by the adsorption of positively charges species. Clays have been attracted attention due to the heterogeneity of their surfaces and some have been found to possess the ability to adsorb ions from solutions and release them later, when the conditions change [24]. Studies have shown that natural clay is an appropriate adsorbent for heavy metal removal due to its efficiency, low cost and availability [25]. The adsorption capabilities of natural clay are attributable to their high surface area and exchange capacities [26]. Among different applications of clay, is the removal of the radionuclides which are troublesome waste materials in nuclear industry [27-29].

The present work was performed in order to investigate and introduce the natural clay obtained from Suez Gulf, Suez city, Egypt, as a new low cost, environmental friendly and highly effective adsorbent material for practical use in removal of Th(IV), Ce(IV), La(III) and Sr(II). The physicochemical properties of the clay were studied using different characterization techniques such as X-ray fluorescence (XRF), X-ray diffraction (XRD), FT-IR and scanning electron microscopy (SEM). The comparative adsorptive features with reference to initial metal ion concentration, clay dose, $\mathrm{pH}$, shaking time, and temperature were investigated. 
Table 1. The approximate percentage of the clay minerals.

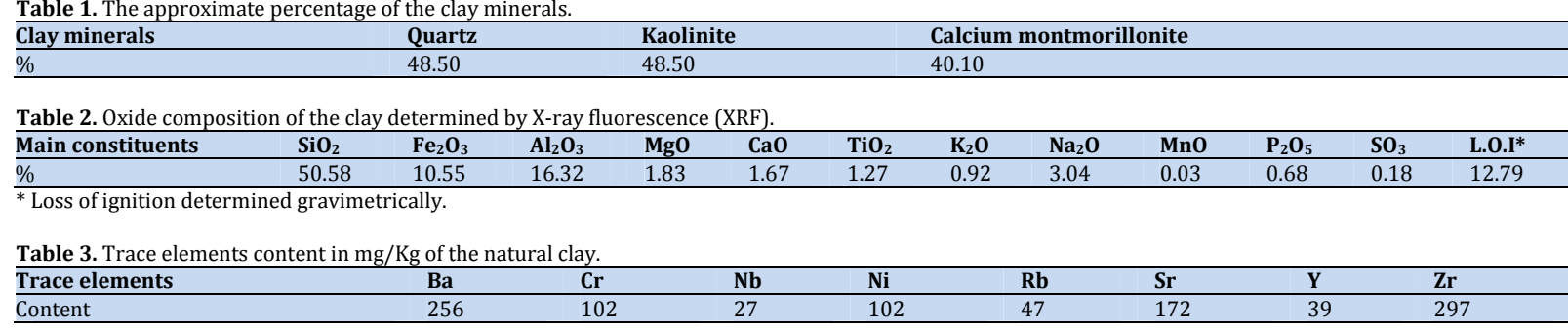

\section{Experimental}

The raw clay sample was obtained from Suez Gulf, Suez city, Egypt. It was first dried and sieved (200-mesh), then washed with bi-distilled water for several times to remove any dust and other water-soluble impurities. The washed sample was dried in electric oven at $398 \mathrm{~K}$ for $24 \mathrm{~h}$ and then placed in a desiccator. Arsenazo III, methylene blue, $\mathrm{Th}\left(\mathrm{NO}_{3}\right)_{4} \cdot 5 \mathrm{H}_{2} \mathrm{O}$, $\left(\mathrm{NH}_{4}\right)_{2}\left[\mathrm{Ce}\left(\mathrm{NO}_{3}\right)_{6}\right], \mathrm{La}\left(\mathrm{NO}_{3}\right)_{3} \cdot 6 \mathrm{H}_{2} \mathrm{O}$ and $\mathrm{Sr}\left(\mathrm{NO}_{3}\right)_{2}$ were obtained from Aldrich Co. All chemicals used were of analytical reagent grade. A metal stock of Th(VI), Ce(IV), La(III) and Sr(II) (2000 $\mathrm{mg} / \mathrm{L}$ ) was prepared by dissolving the respective metal salt in bi-distilled water. Standard buffer solutions $(\mathrm{pH}=4,7$ and 9) were used to calibrate the $\mathrm{pH}$-meter model 8521 from Hanna Instruments. The chemical composition of clay was investigated by X-ray fluorescence (XRF) using an Axios Sequential WD-XRF Spectrometer manufactured by PANanalytical 2005, Netherlands. FT-IR (KBr Pellets) was carried out on a Unicam-Mattson 1000 FT-IR. Surface morphology of clay was investigated by scanning electron microscopy (SEM) by LEO SEM 1430 VP microscope supplied with an EDX detector. X-ray diffraction (XRD) was carried out using Bruker AXS D8 Advance X-ray diffractometer with $\mathrm{CuK} \alpha$ radiation $\lambda=1.54180 \AA$.

\subsection{Determination of Th(IV), Ce(IV), La(III) and Sr(II)}

A simple and sensitive spectrophotometric methods based on colored complexes of Arsenazo III with Th(IV) [30], Ce(IV), $\mathrm{La}(\mathrm{III})$ [31] and $\mathrm{Sr}$ (II) [32] in aqueous medium were used for their determination. The concentration of metal ions in the solution before and after adsorption was determined with a Unicam UV2-300 UV-Vis spectrophotometer, by measuring the absorbance at $\lambda_{\max }$ of $660 \mathrm{~nm}$ for Th(IV), $620 \mathrm{~nm}$ for Ce(IV) and $\mathrm{La}(\mathrm{III})$ and $643 \mathrm{~nm}$ for $\mathrm{Sr}(\mathrm{II})$.

\subsection{Adsorption studies}

The adsorption experiments of Th(IV), Ce(IV), La(III) and $\operatorname{Sr}($ II) onto clay in liquid-solid system were studied using a batch technique. The batch studies were carried out in a reciprocating thermostated water bath shaker (GFL-1083 model). The shaking rate was the same for all experiments. The $\mathrm{pH}$ of the solution was adjusted prior to the experiments by addition of negligible amount of $\mathrm{NH}_{4} \mathrm{OH}$ or $\mathrm{HNO}_{3}(0.1 \mathrm{M}) .0 .1 \mathrm{~g}$ of clay and $10 \mathrm{~mL}$ of standard metal ion solution were shaken at different temperature for various mixing time. Centrifugation was applied to separate solid phase from liquid at $300 \mathrm{rpm}$ for 40 minutes. The amount of sorbed metal ion was estimated from the difference of the metal ion concentration in the aqueous phase before and after the adsorption using Arsenazo III method as complexing agent against reagent blank. For calculating the metal ion concentration, the adsorption of solution was compared with a working curve that was a plot of absorbance versus standard concentration of metal ion. The results of experiments were expressed in terms of adsorption percentage, using the Equation 1.
Adsorption $\%=\frac{\mathrm{C}_{\mathrm{i}}-\mathrm{C}_{\mathrm{e}}}{\mathrm{C}_{\mathrm{i}}} \times 100$

where $\mathrm{C}_{\mathrm{i}}$ and $\mathrm{C}_{\mathrm{e}}$ are the initial and equilibrium concentration of metal ions in solution, respectively.

Distribution coefficient $\left(\mathrm{K}_{d}\right)$ is defined as the ratio of the concentration of the radionuclide in the sorbent and in the solution at equilibrium. The distribution coefficients were calculated by using the Equation 2.

$\mathrm{K}_{\mathrm{d}}=\frac{\mathrm{C}_{\mathrm{i}}-\mathrm{C}_{\mathrm{e}}}{\mathrm{C}_{\mathrm{e}}} \frac{\mathrm{V}}{\mathrm{m}} \mathrm{mL} / \mathrm{g}$

where V: the volume of the solution $(\mathrm{mL})$ and $\mathrm{m}$ is the grams of the clay adsorbent.

The influence of different parameters such as initial metal ion concentration, clay dose, $\mathrm{pH}$, contact time, and temperature on the adsorption process, have been investigated by calculating adsorption \% onto the clay by changing one parameter and keeping other parameters constant. All the experiments have been carried out in triplicate. The centrifuge of the solution was carried out at high speed to avoid any solid particles in the aqueous phase.

\section{Results and discussion}

\subsection{Characterization of clay}

\subsubsection{Mineralogical and chemical composition}

The mineralogical composition of the raw clay was investigated by means of the X-ray diffraction (XRD), Figure 1. The results are listed in Table 1 . Chemical composition for the natural clay was determined by using X-ray fluorescence (XRF) and the data are listed in Tables 2 and 3.

\subsubsection{Determination of cation exchange capacity (CEC)}

Layer charge is one of the most important parameters of clay minerals. It determines material properties, which are important for industrial applications. These are mainly rheology properties, swelling, shrinking and the capacity to retain cations. Permanent charge arises from isomorphic substitutions in the tetrahedral and octahedral sheets. For example, each replacement of $\mathrm{Si}(\mathrm{IV})$ by $\mathrm{Al}(\mathrm{III})$ in tetrahedrons or $\mathrm{Al}(\mathrm{III})$ by $\mathrm{Mg}(\mathrm{II})$ in octahedrons contributes to the negative layer charge in an amount equal to that of one electron (e). The permanent charge, which is related to the mineral structure and composition and doesn't change with reaction conditions over a wide $\mathrm{pH}$ range in aqueous solutions. Variable charge originates from reactions of specific functional groups at clay particle edges. These functional groups can react as either Brönsted acids or base [33].

Cation exchange capacity (CEC) is a measure of the cations, which balance the negative charge sites of the clay [34]. CEC is usually expressed as the retained excess cation quantity divided by the sample mass. 


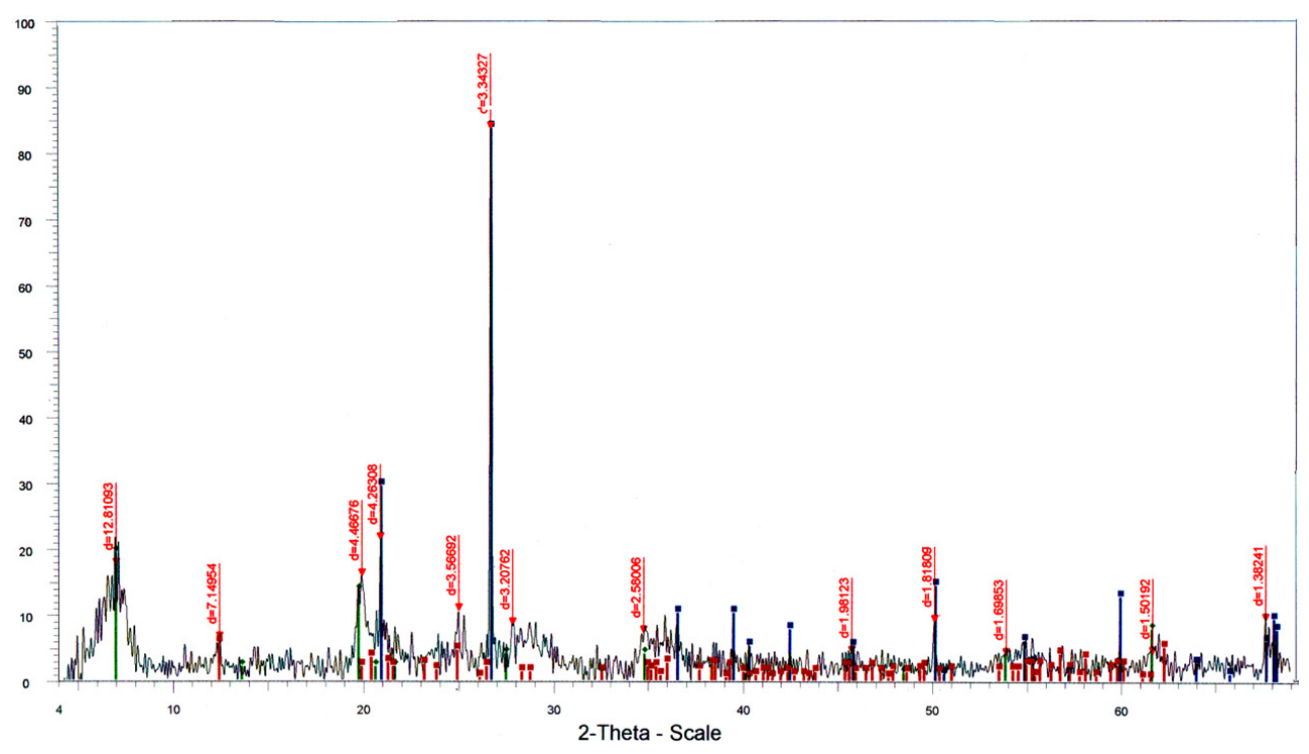

Figure 1. XRD pattern of natural clay.

CEC determination of clay was based on exchange with methylene blue (MB). The solution concentration was determined using spectrophotometry at $665 \mathrm{~nm}$ by applying Lambert-Beer law and using the known molar absorption coefficient $\left(\varepsilon=95,000 \mathrm{~mol}^{-1} \mathrm{~L} \mathrm{~cm}^{-1}\right)$ for the calculation [35]. $200 \mathrm{mg}( \pm 0.5 \mathrm{mg}$ ) clay was mixed with $20 \mathrm{~mL}$ bi-distilled water and $10 \mathrm{~mL}$ of $\mathrm{MB}$ solution. The excess $\mathrm{MB}$ was sufficient to guarantee complete exchange of the inorganic cations. The suspensions were separated from the supernatants using filtration through $0.2 \mu \mathrm{m}$ pore size filters. The concentrations of MB in supernatants were determined using spectrophotometry with double-distilled water as the control. The CEC was calculated from the difference between the amount of dye added and the amount of unadsorbed dye and the mass of clay used, which was determined gravimetrically after drying overnight at $105^{\circ} \mathrm{C}$. The CEC values obtained using this method is identified as $\mathrm{CEC}_{(\mathrm{MB})}$. The $\mathrm{CEC}$ value for the clay was found to be $2.35 \mathrm{~mol} / \mathrm{g}$.

\subsubsection{FT-IR characterization}

The clay was also characterized by FT-IR spectroscopy. FTIR spectra were collected in the mid-IR range from 4000 to 400 $\mathrm{cm}^{-1}$ with a resolution of $1 \mathrm{~cm}^{-1}$. The FT-IR spectra of both natural clay before and after adsorption of Th(IV) as an illustrative example are shown in Figures 2 and 3.

The IR band in the region 3695-3449 $\mathrm{cm}^{-1}$ represents the inner surface-OH stretching vibration and those at 1036, 916 and $794 \mathrm{~cm}^{-1}$ represent the $\mathrm{Si}-\mathrm{O}, \mathrm{Al}-\mathrm{OH}$ bending vibrations and Si-O stretching vibration, respectively [36,37]. The absorption bands at 1642 and $468 \mathrm{~cm}^{-1}$ represent $\mathrm{OH}$ bending of water and $\mathrm{Si}-\mathrm{O}-\mathrm{Si}$ deformation/Fe-O stretching, while the bands at 525 and $427 \mathrm{~cm}^{-1}$ are due to Al-O-Si stretching vibration and stretching vibration of structural $\mathrm{OH}$ groups [38]. Water give a broad band at $3449 \mathrm{~cm}^{-1}$ corresponding to the $\mathrm{H}_{2} \mathrm{O}$-stretching vibrations [39]. The FT-IR pattern show no difference between clay before and after interaction with Th(IV) which has been suggested a physical adsorption phenomenon occurs as a result of attraction forces between the negatively charged clay surface and metal ions under investigation. Such behavior was also observed in case of $\mathrm{Ce}(\mathrm{IV}), \mathrm{La}(\mathrm{III})$ and $\mathrm{Sr}(\mathrm{II})$.

\subsubsection{SEM studies}

The heterogeneity of the clay surface before and after adsorption of Th(IV) as an illustrative example of studied ions has been investigated by the scanning electron microscope to probe the change in morphological features of clay before and after adsorption experiments, Figure 4.

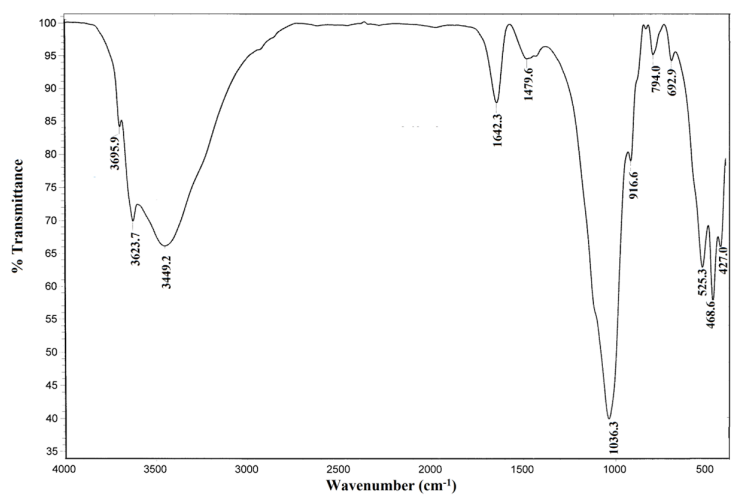

Figure 2. FT-IR spectrum of pure natural clay.

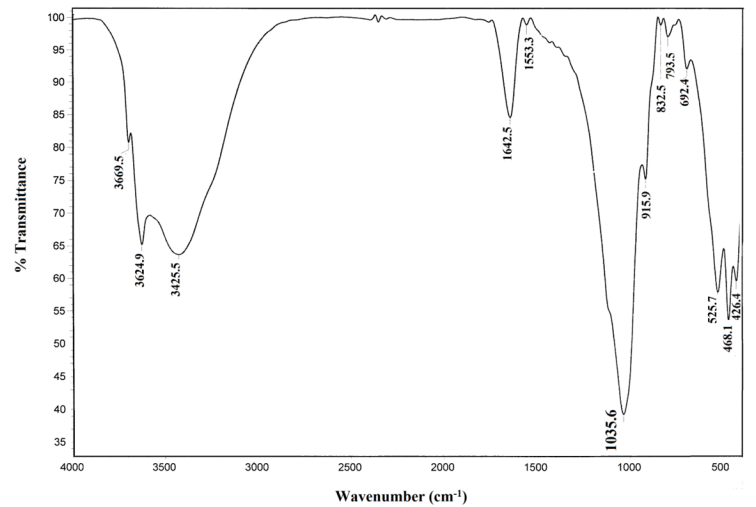

Figure 3. FT-IR spectrum of natural clay after adsorption of Th(IV) ( $\mathrm{C}_{\mathrm{Th}(\mathrm{IV})}$ $100 \mathrm{mg} / \mathrm{L}$, clay dose $100 \mathrm{mg}, 298 \pm 1 \mathrm{~K}, \mathrm{pH}=4$ ). 


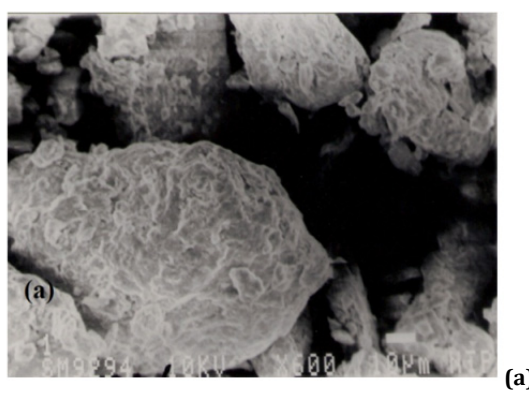

(a)

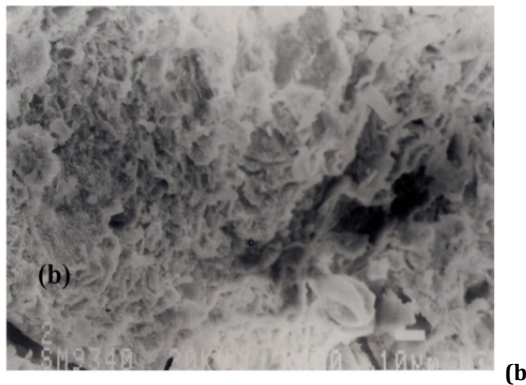

(b)

Figure 4. SEM micrograph of natural clay (a) before and (b) after Th(IV) adsorption.

It was clearly observed that, the surface morphology of clay after adsorption is different from that before adsorption. The natural clay shows loose aggregates with porous structure. After adsorption, large amounts of pores on clay disappeared with an increase in adsorption time and as the adsorption time reaches 60 minutes, the surface of the clay demonstrates compact aggregates and doesn't change visibly with further adsorption. SEM results have been showed that, the surface morphology of the clay changed evidently during the adsorption process, indicating that an important interaction at the metal-interface has been occurred in the experimental conditions.

\subsection{Adsorption experiments}

\subsubsection{Effect of initial concentration}

The relative metal ion uptake onto clay as a function of metal ion concentration has been studied from 20 to $600 \mathrm{mg} / \mathrm{L}$ (Figure 5). Maximum adsorption was found in the range 20-100 $\mathrm{mg} / \mathrm{L}$ and then decreased with increasing initial concentration. In further experiments concentration of $100 \mathrm{mg} / \mathrm{L}$ was used.

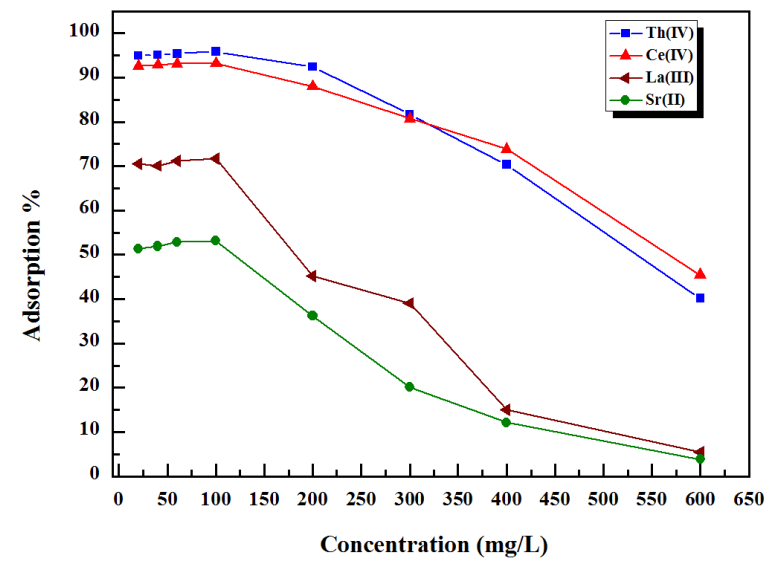

Figure 5. Effect of initial concentration on adsorption \% of metal ions onto natural clay (clay dose $100 \mathrm{mg}, 298 \pm 1 \mathrm{~K}, \mathrm{pH}=4$ ).

\subsubsection{Effect of clay dose}

The effect of clay dose on adsorption \% has been studied by changing the clay dose in the range 100-200 mg, Figure 6 . The data showed that, adsorption \% of metal ions increased with increasing clay dose and adsorption \% almost constant at higher dosages than $100 \mathrm{mg}$. This was attributed to as the clay dose increases, a greater number of active sites for exchange or adsorption of metal ions on the mineral surface has been formed. Hence remaining parts of experiments were carried out with the clay dose of $100 \mathrm{mg}$.

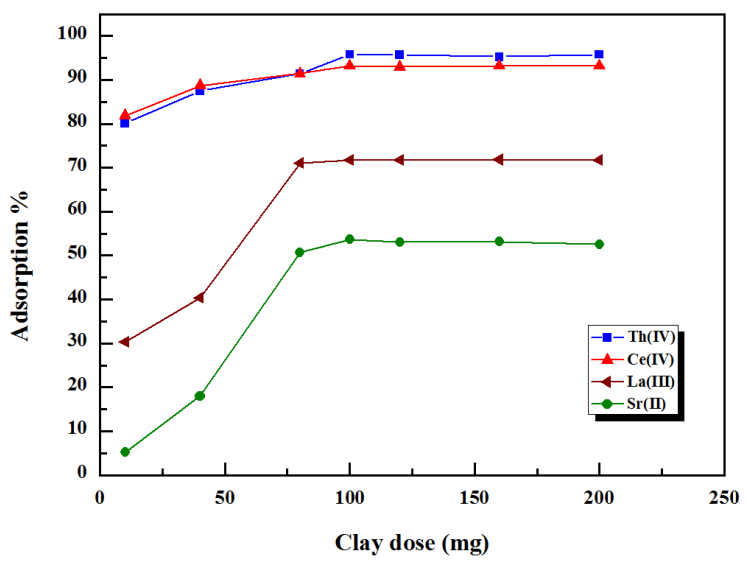

Figure 6. Effect of clay dose on adsorption \% of metal ions onto natural clay $\left(\mathrm{C}_{\mathrm{M}}=100 \mathrm{mg} / \mathrm{L}, 298 \pm 1 \mathrm{~K}, \mathrm{pH}=4\right)$.

\subsubsection{Effect of shaking time}

The influence of shaking time on the metal ions adsorption $\%$ onto clay was studied. Samples were shaken in the range of 5-180 min., Figure 7. As seen from Figure 7, adsorption \% increases with increasing shaking time and equilibrium has been attained within $60 \mathrm{~min}$. The equilibrium has been attained when the adsorption sites on the clay minerals were quickly covered by the metal ions and the adsorption rate became dependent on the rate at which the metal ions were transported from the bulk liquid phase to the actual adsorption site [40].

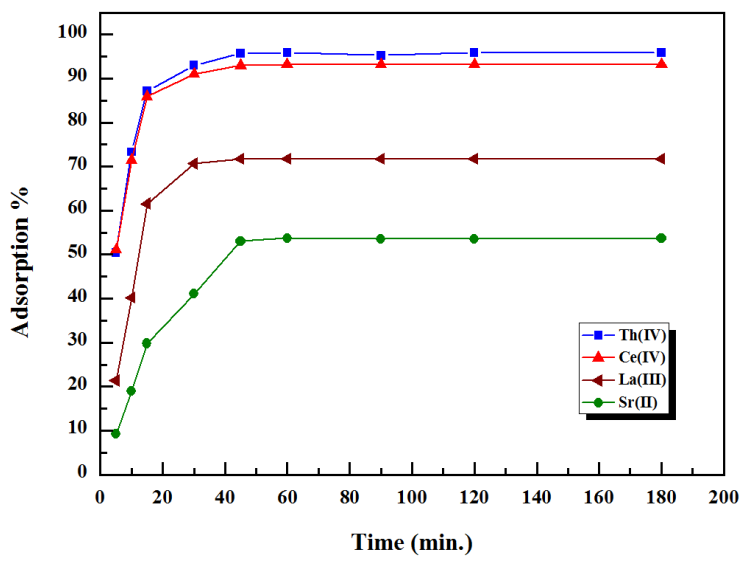

Figure 7. Effect of contact time on adsorption $\%$ of metal ions onto natural clay ( $\mathrm{C}_{\mathrm{M}}=100 \mathrm{mg} / \mathrm{L}$, clay dose $\left.100 \mathrm{mg}, 298 \pm 1 \mathrm{~K}, \mathrm{pH}=4\right)$.

\subsubsection{Effect of $\mathrm{pH}$ of the solution on sorption}

The results emphasized that, with increase in $\mathrm{pH}$ of solution, the adsorption $\%$ increases for all ions, Figure 8 . The data revealed that, maximum adsorption \% onto clay at was 
achieved $\mathrm{pH}=4$ and the remains level with increasing $\mathrm{pH}$ values at $\mathrm{pH}>4$. The increase in adsorption $\%$ with increase in $\mathrm{pH}$ can be explained on the basis of increase in the negative surface charge of clay. The variation of surface charge density with increasing $\mathrm{pH}$ can be a result of the ionization of surface silanol groups [40]. With increasing adsorption density hydrogen ions pass from surface to solution, and thus change the $\mathrm{pH}$ of the bulk solution. The process can be expressed by Scheme 1.

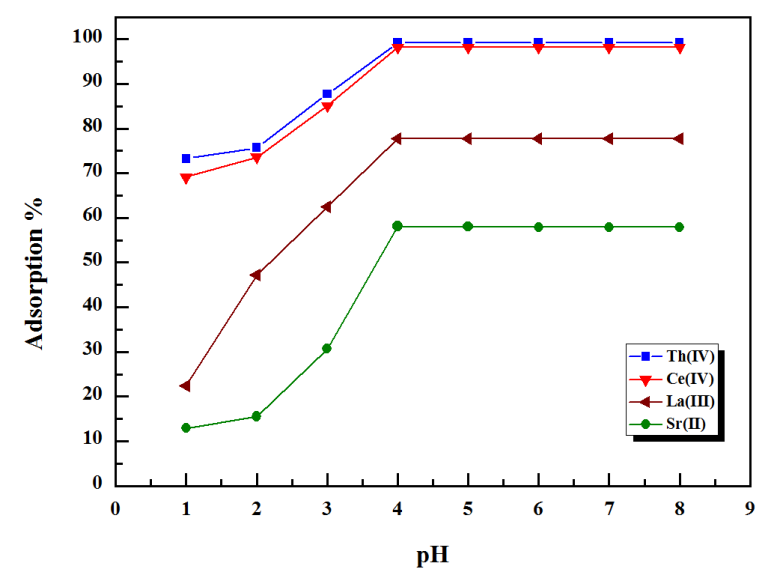

Figure 8. Effect of $\mathrm{pH}$ on adsorption \% of metal ions onto natural clay $\left(\mathrm{C}_{\mathrm{M}}=100 \mathrm{mg} / \mathrm{L}\right.$, clay dose $\left.100 \mathrm{mg}, 298 \pm 1 \mathrm{~K}\right)$.

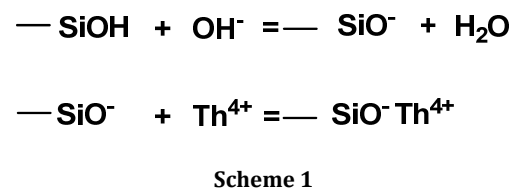

At $\mathrm{pH}<4$, thorium shows a small tendency to hydrolyze, and the exchangeable thorium ion (Th(IV)) dominates [41,42], and as the $\mathrm{pH}$ increases mononuclear species such as $[\mathrm{ThOH}]^{3+}$, $\left[\mathrm{Th}(\mathrm{OH})_{2}\right]^{2+}$ and $\left[\mathrm{Th}(\mathrm{OH})_{3}\right]^{+}$, as well as polynuclear-polymeric hydrolysis products of the general type $\left[\mathrm{Th}_{\mathrm{x}}(\mathrm{OH})_{\mathrm{y}}\right]^{(4 \mathrm{x}-\mathrm{y})+}$ are formed. The hydroxyl number of these species depends on the thorium concentration and rises rapidly with increasing $\mathrm{pH}$. In case of cerium, Ce(IV) forms several hydroxy complexes, such as $[\mathrm{Ce}(\mathrm{OH})]^{3+}$ and $\left[\mathrm{Ce}(\mathrm{OH})_{2}\right]^{2+}[41,43]$. The number of hydroxy groups depends on the $\mathrm{pH}$ of solution. Furthermore the hydroxy complexes show a tendency to form dimers $[\mathrm{Ce}(\mathrm{OH}) \mathrm{Ce}]^{7+}$, trimers $[\mathrm{Ce}(\mathrm{OH}) \mathrm{Ce}(\mathrm{OH}) \mathrm{Ce}]^{10+}$ and high polymers having an average charge per single cerium atom less than 4. On the other hand, Lanthanum do not readily hydrolyze, and hydrolysis seems to be negligible below $\mathrm{pH}=6.0$ [44]. La(III) tend to bind the water molecules and the most common form obtained is $\left[\mathrm{La}\left(\mathrm{H}_{2} \mathrm{O}\right)_{6}\right]^{3+}[45]$. Based on hydrolysis constants of lanthanum, up to $\mathrm{pH}=6$, no hydrolysis take places and all the lanthanum would be present as La(III) ions [46]. At $\mathrm{pH}<6$, strontium mainly occurs as $\mathrm{Sr}(\mathrm{II})$ and other possible form is $\mathrm{SrOH}^{+}[47]$.

In present study, it has been supposed that there is an electrostatic effect between the positively charged ions and the negative charged clay. The obtained data of $\mathrm{pH}$ study, reveals that metal uptake increases with increase in $\mathrm{pH}$, and the order of metal ion adsorption onto clay nearly at all the $\mathrm{pH}$ is $\mathrm{Th}(\mathrm{IV})>$ $\mathrm{Ce}(\mathrm{IV})>\mathrm{La}(\mathrm{III})>\mathrm{Sr}(\mathrm{II})$. Furthermore, the reason for low adsorption in acidic solution is the competition between the excess of $\mathrm{H}^{+}$ions in the medium and positively charged cationic species present in solution [48]. Also, higher acid concentrations suppress hydrolysis of the metal ions. In addition, as $\mathrm{pH}$ increase there is a decrease of positive surface charge, which results in lower columbic repulsion of the sorbing metal ions [49]. Moreover at low $\mathrm{pH}$ values, the surface of the sorbent would be closely associated with hydronium ions $\left(\mathrm{H}_{3} \mathrm{O}^{+}\right)$which hinder the access of metal ions to the surface functional group. Consequently the adsorption $\%$ may decrease at low $\mathrm{pH}[49,50]$.

\subsubsection{Effect of temperature}

The adsorption dependence on temperature $(298,318$ and $338 \mathrm{~K}$ ) is presented in Figure 9. As seen from this figure, adsorption \% decreased with increasing temperature. The adsorption at the studied temperatures usually completed when the surface of clay is covered with a monolayer of metal ion. After the equilibrium, the decrease in adsorption percent with increase in the temperature gave an indication of the exothermic nature of adsorption [51].

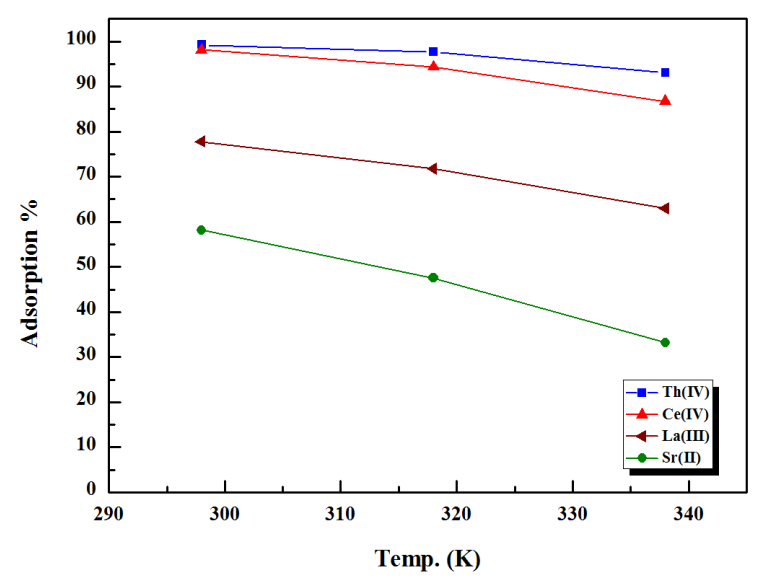

Figure 9. Effect of temperature on adsorption $\%$ of metal ions onto natura clay $\left(\mathrm{C}_{\mathrm{M}}=100 \mathrm{mg} / \mathrm{L}\right.$, clay dose $\left.100 \mathrm{mg}, \mathrm{pH}=4\right)$.

The decrease in adsorption \% with increasing temperature support the mechanism of adsorption may be mainly of physical nature. One possible interpretation of exothermicity of enthalpy of adsorption is that the metal ions with low hydration energies are weakly solvated in water. The adsorption of metal ions may require at least a partial decomposition of their hydration shell, a process that requires energy input. If the exothermicity associated with the adsorption of metal ions on clay exceeds the dehydration energy of metal ions, then the overall energy balance will lead to exothermic behavior. When the value of $\Delta H^{\circ}$ is lower than 40 $\mathrm{kJ} / \mathrm{mol}$, the adsorption can be accepted as a physical process [52].

The thermodynamic parameters $\left(\Delta H^{\circ}\right)$ and $\left(\Delta S^{\circ}\right)$ were calculated from the slopes and intercepts of $\ln K_{d}$ vs. 1000/T plot (Figure 10) by using Equation 3, and the Gibbs free energy, $\left(\Delta G^{\circ}\right)$ of specific adsorption was calculated from thermodynamic equilibrium adsorption constants using Equation 4.

$\operatorname{Ln} K_{\mathrm{d}}=\frac{\Delta S^{\circ}}{\mathrm{R}}-\frac{\Delta H^{\circ}}{\mathrm{RT}}$

$\Delta G^{\circ}=-R T \operatorname{Ln} K_{d}$

where $\mathrm{R}(8.3145 \mathrm{~J} / \mathrm{mol} . \mathrm{K})$ is ideal gas constant and $\mathrm{T}(\mathrm{K})$.

The relevant data calculated from Equations 3 and 4 are listed in Table 4. The calculated values of $\Delta H^{\circ}$ were -37.89 , $-33.31,-21.40$ and $-15.08 \mathrm{~kJ} / \mathrm{mol}$, respectively. 
Table 4. Thermodynamic parameters of adsorption system.

\begin{tabular}{|c|c|c|c|c|c|}
\hline \multirow{2}{*}{ Elements } & \multirow{2}{*}{$\Delta H^{\circ}(\mathrm{kJ} / \mathrm{mol})$} & \multirow{2}{*}{$\Delta S^{\circ}(\mathrm{kJ} / \mathrm{mol})$} & \multicolumn{3}{|c|}{$\Delta G^{\circ}(\mathrm{kJ} / \mathrm{mol})$} \\
\hline & & & $298 \mathrm{~K}$ & $318 \mathrm{~K}$ & $338 \mathrm{~K}$ \\
\hline$\overline{\mathrm{Th}(\mathrm{IV})}$ & -37.89 & 81.73 & -23.51 & -22.02 & -20.20 \\
\hline $\mathrm{Ce}(\mathrm{IV})$ & -33.31 & 74.41 & -21.18 & -19.59 & -18.21 \\
\hline $\mathrm{La}(\mathrm{III})$ & -21.4 & 30.48 & -14.49 & -14.64 & -14.41 \\
\hline $\operatorname{Sr}(\mathrm{II})$ & -15.08 & 1.76 & -12.21 & -11.89 & -10.96 \\
\hline
\end{tabular}

Those data have been suggested that, the adsorption process onto clay was an exothermic and physical adsorption process. Physical adsorption is caused mainly by Vander Waals forces and electrostatic forces between adsorbate molecules and atoms which compose the adsorbent surface [53]. The low values of the entropy $\left(\Delta S^{\circ}\right)$ for clay have been indicated more constraint on the mobility of the adsorbate molecules. The positive values of entropy change $\left(\Delta S^{\circ}\right)$ reflects the affinity of clay toward metal ions in the solutions and may suggest some structural changes in the sorbents $[54,55]$. The decrease in $\Delta G^{\circ}$ with decreasing temperature has been indicated more efficient adsorption at lower temperature. It is also evident from the results that, the free energy $\left(\Delta G^{\circ}\right)$ values of the adsorption of metal ions on clay are negative, showing that adsorption processes are spontaneous in nature.

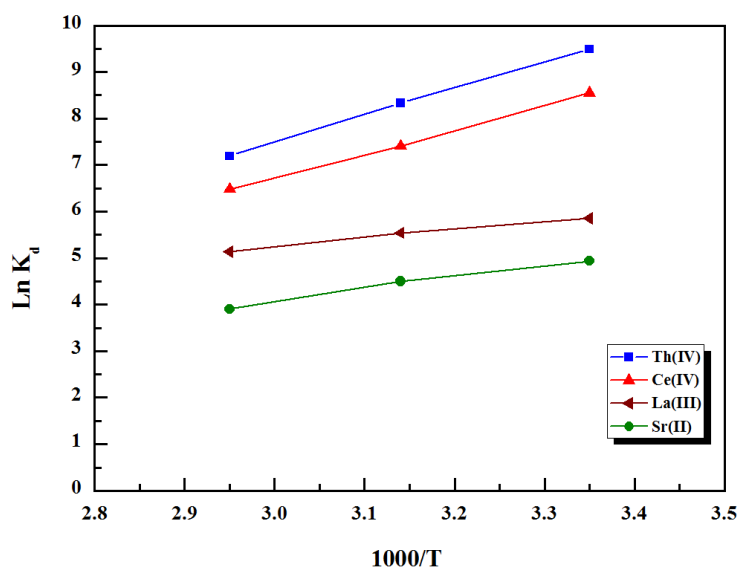

Figure 10. Plot of $\ln K_{d}$ vs. 1000/T for metal ions adsorption.

\subsubsection{Efficiency of separation}

The process of separation and purification of mixture of radionuclides is of vital importance. One of the well-known processes of separation is the adsorption process which is extensively used. The separation efficiency may be expressed by the separation factor, which $(\alpha)$ is defined by the ratio of the distribution coefficients (Equation 5).

$\alpha=\frac{\left(K_{d}\right)_{M}}{\left(K_{d}\right)_{N}}$

where $\left(K_{d}\right)_{M}$ and $\left(K_{d}\right)_{N}$ are the distribution coefficients values of the elements $\mathrm{M}$ and $\mathrm{N}$, respectively. By definition, the value of the separation factor is always greater than unity. The separation factor is sometimes also called the 'selectivity'. The use of this expression is discouraged. As the separation factor increase, the selectivity for the two species $\mathrm{M}$ and $\mathrm{N}$ increase. It has been shown from the data, maximum uptake occurred at $\mathrm{pH}=4$, so $(\alpha)$ has been calculated at $\mathrm{pH}=4$, Table 5 . The data revealed that, the clay is more efficient for separation of $\operatorname{Sr}(\mathrm{II})$ from Th(IV) than La(III) and Ce(IV) from Th(IV).

These data produced a good method for separation of $\operatorname{Sr}($ II) (fission product) from $\mathrm{Th}(\mathrm{IV})$ fuel where Sr(II) with its long half-life is considered to be the more critical isotope, having a propensity to be strongly retained within the living organisms, mainly in the bones, being a source of long term radiation of bone marrow.

Table 5. Separation factor at $\mathrm{pH}=4$

\begin{tabular}{lllll}
\hline \multirow{2}{*}{ Parameters } & \multicolumn{4}{c}{ Element } \\
\cline { 2 - 5 } & Th(IV) & Ce(IV) & La(III) & Sr(II) \\
\hline $\mathrm{K}_{\mathrm{d}}$ & 13226.795 & 5166.759 & 347.234 & 138.3708 \\
$\alpha$ & - & $2.559 \mathrm{a}$ & $38.092^{\mathrm{b}}$ & $95.590^{\mathrm{c}}$ \\
\hline $\mathrm{a}\left(\mathrm{K}_{\mathrm{d}}\right)_{\mathrm{Th}(\mathrm{IV})} /\left(\mathrm{K}_{\mathrm{d}}\right)_{\mathrm{Ce}(\mathrm{IV})}$ & & & \\
$\mathrm{b}\left(\mathrm{K}_{\mathrm{d}}\right)_{\mathrm{Th}(\mathrm{IV})} /\left(\mathrm{K}_{\mathrm{d}}\right)_{\mathrm{La}(\mathrm{III})}$ & & & \\
c $\left(\mathrm{K}_{\mathrm{d}}\right)_{\mathrm{Th}(\mathrm{IV})} /\left(\mathrm{K}_{\mathrm{d}}\right)_{\mathrm{Sr} \text { (II) }}$ & & &
\end{tabular}

\section{Conclusion}

The efficiency of the natural clay obtained from Suez gulf, Suez city, Egypt for the adsorption of Th(IV), Ce(IV), La(III) and $\mathrm{Sr}$ (II) from aqueous solution was investigated using batch adsorption technique under different experimental conditions. The reported results have been showed that the adsorption varied strongly by $\mathrm{pH}$ and metal ion concentration. The effect of $\mathrm{pH}$ study, revealed that metal uptake increase with increase in $\mathrm{pH}$, and the order of metal ion adsorption onto clay nearly at all the studied $\mathrm{pH}$ was $\mathrm{Th}(\mathrm{IV})>\mathrm{Ce}(\mathrm{IV})>\mathrm{La}(\mathrm{III})>\mathrm{Sr}(\mathrm{II})$ at $\mathrm{pH}=4$. Maximum metal ion uptake capacity of clay obtained from batch studies was $99.24,98.21,77.76$ and $57.94 \%$, respectively. The thermodynamic parameters $\Delta H^{\circ}, \Delta S^{\circ}$ and $\Delta G^{\circ}$ were evaluated as well. The calculated values of $\Delta H^{\circ}$ were found to be of negative values less than $40 \mathrm{~kJ} / \mathrm{mol}$, which suggested that, the adsorption of metal ions onto clay surface was of exothermic and physical nature. Furthermore, the negative values of $\Delta G^{\circ}$ have been indicated the spontaneity. Finally, the, separation factor $(\alpha)$ of $\mathrm{Th}(\mathrm{IV}) / \mathrm{Ce}(\mathrm{VI}), \mathrm{Th}(\mathrm{IV}) / \mathrm{La}(\mathrm{III})$ and $\mathrm{Th}(\mathrm{IV}) / \mathrm{Sr}$ (II) were calculated and found to be 2.559, 38.092, 95.590 , respectively. This study has been showed that the clay has a high adsorption capacity to remove Th(IV), Ce(IV), La(III) and $\mathrm{Sr}$ (II) from aqueous solutions and it can be used as an efficient, low cost adsorbent material for the adsorption of radionuclides and toxic metals from contaminated aqueous solutions. The reported method showed high competitive, economic, expediency and ecological safety.

\section{Acknowledgements}

The authors are highly thankful to Chemistry Department, Faculty of Science, Ain Shams University for providing laboratory facilities and for support of this work. Also, the authors gratefully acknowledge Professor Gamal Saber El-Safhy (Chemistry Department, Faculty of Science, Ain Shams University) for his the helpful discussion.

\section{References}

[1]. Humeinicu, D.; Drochioiu G. J. Radioanal. Nucl. Chem. 2004, 260, 291293.

[2]. Choppin, G. R. Radiochim. Acta 1999, 85, 89-96.

[3]. Bhattacharyya, K. G.; Sen, G. S. Colloids Surf. 2006, 277, 191-200.

[4]. Sharma, P.; Tomar, R. Micropor. Mesopor. Mat. 2008, 116, 641-652.

[5]. Babel, S.; Kurniawan, T. A. J. Hazard. Mater. 2003, 97, 219-243.

[6]. Naseem R.; Tahir, S. S. Water Res. 2001, 35, 3982-3986.

[7]. Tsoufis, T.; Xidas, P.; Jankovic L.; Gournis D.; Saranti A.; Bakas T.; Karakassides M. A. Diam. Relat. Mater. 2007, 16, 155-160.

[8]. Karadag, D.; Koc, Y.; Turan, M.; Ozturk, M. J. Hazard. Mater. 2007, 144, 432-437.

[9]. Kozaki, T.; Sata, H.; Nakajima, M.; Kato, H.; Sato, S.; Ohashi, H. J. Nucl. Mater. 1999, 270, 265-272.

[10]. Wang, X. K.; Tan, X. L.; Chen, C. L.; Chen, L. J. Nucl. Mater. 2005, 345 184-191.

[11]. Wang, X. L.; Chen, C. L.; Zhou, X.; Tan, X. L.; Hu, W. P. Radiochim. Acta 2005, 93, 273-278.

[12]. Xu, D.; Chen, C. L.; Wang, X. K. J. Radioanal. Nucl. Chem. 2006, 267, $357-$ 362.

[13]. Montavon, G.; Rabung, T.; Geckeis, H.; Grambow, B. Environ. Sci Technol. 2004, 38, 4312-4318.

[14]. Takahashi, Y.; Kimura, T.; Minai, Y. Geochim. Cosmochim. Acta 2002, $66,1-12$.

[15]. Wang, X. K.; Chen, Y. X.; Wu, Y. C. Appl. Radiat. Isotopes 2004, 60, 963- 
969.

[16]. Wang, X. K.; Chen, C. L.; Du, J. Z.; Tan, X. L.; Xu, D.; Yu, S. M. Environ. Sci. Technol. 2005, 39, 7084-7088.

[17]. Wang, X. K.; Zhou, X.; Du, J. Z.; Hu, W. P.; Chen, C. L.; Chen, Y. X. Surf. Sci. 2006, 600, 478-483.

[18]. Chen, C. L.; Wang, X. K. Appl. Radiat. Isot. 2007, 65, 155-163.

[19]. Reiller, P.; Casanova, F.; Molin, V. Environ. Sci. Technol. 2005, 39, 1641-1648.

[20]. Tan, X. L.; Wang, X. K.; Chen, C. L.; Sun A. H. Colloid Surf. A 2007, 296, 109-116.

[21]. Xu, D.; Wang, K. X.; Chen, C. L.; Zhou, X.; Tan, X. L. Radiochim. Acta 2006, 94, 429-434.

[22]. Cuevas, J.; Leguey, S.; Garralon, A.; Rastrero, M. R.; Procopio, J. R.; Sevilla, M. T.; Jimenez, N. S.; Abad, R. R.; Garrido, A. Appl. Clay Sci. 2009, 42, 497-509.

[23]. Visekruna, A.; Strkalj, A.; Pajc, L. M. Holist. Approach Environ. 2011, 1, 29-37.

[24]. Forestier, L. L.; Muller, F.; Villieras, F.; Pelletier, M. Appl. Clay Sci. 2010, $48,18-25$.

[25]. Ivan, S.; Velimin, P. Croat. Chem. Acta 1998, 71, 1061-1074.

[26]. Cuevas, J.; Leguey, S.; Garralon, A.; Rastrero, M. R.; Procopio, J. R.; Sevilla, M. T.; Jimenez, N. S.; . Abad, R. R.; Garrido A. Appl. Clay Sci. 2009, 42, 497-509.

[27]. Bronic, J.; Subotic, B. J. Radioanal. Nucl. Chem. 1992, 162, 339-350.

[28]. Tsuji, M.; Mimura, H. J. Mater. Res. 2000, 15, 2849-2856.

[29]. Mitypov, B. B.; Zonkhoeva, E. L.; Kozhevnikova, N. M.; Pashinova, B. V. Russian J. Appl. Chem. 2001, 74, 580-583.

[30]. Onishi, H. Photometric Determination of Traces of Metals, Part IIB: Individual Metals, Magnesium to Zirconium, $4^{\text {th }}$ edition, John Wiley \& Sons Inc., New York, 1989.

[31]. Marczenko, Z.; Balcerzak, M. Separation, preconcentration, and spectrophotometry in inorganic analysis, $1^{\text {st }}$ edition, Elsevier, Amsterdam, 2000

[32]. Michaylova, V.; Kouleva, N. Talanta 1974, 21, 523-532.

[33]. Brown, D. R.; Rhodes C. N. Catal. Lett. 1997, 45, 35-40.

[34]. Tournassat, C.; Greneche, J. M.; Tisserand, D.; Charlet, L. J. Colloid Interface Sci. 2004, 273, 224-233.

[35]. Breen, C.; Rock, B. Clay Miner. 1994, 29, 179-189.

[36]. Adebowale, K. O.; Unuabonah, I. E.; Olu-Owolabi, B. I. J. Hazard. Mater. 2006, 134, 130-139.

[37]. Yuan, P.; Annabi-Bergaya, F.; Tao, Q.; Fan, M.; Liu, Z.; Zhu, J.; He, H.; Chen, T. J. Colloid Interface Sci. 2008, 324, 142-149.

[38]. Eren, E.; Afsin, B. J. Hazard. Mater. 2008, 151, 682-691.

[39]. Bhattacharyya, K. G.; Sen, G. S. Appl. Clay Sci. 2008, 41, 1-9.

[40]. Alkan, M.; Demirbaș, 0.; Doğan, M. Micropor. Mesopor. Mat. 2005, 84, 192-200.

[41]. Baes, C. F.; Robert, E. M. The hydrolysis of cations, Wiley-Inter science Publications, New York, 1976.

[42]. Sinha, S. P. Complexes of Th rare Earths, $1^{\text {st }}$ edition, Pergamon Press, London, 1966.

[43]. Danessi, P. R. Acta Chem. Scand. 1967, 21, 143-151.

[44]. Topp, N. E. The Chemistry of the Rare Earth Elements. Elsevier, Amsterdam, 1965

[45]. Brookins, D. G. Aqueous geochemistry of rare earth elements. In: Lipin, B. R.; McKay G. A. (Eds.). Geochemistry and Mineralogy of Rare Earth Elements, (Reviews in Mineralogy vol. 21). The Mineralogical Society of America, Washington, DC, 1989.

[46]. Bouyer, F.; Sanson, N.; Destarac, M.; Gerardin, C. New J. Chem. 2006, 30, 399-409.

[47]. Bowen, H. J. M. Trace Elements in Biochemistry. London-New York, 1966.

[48]. Parks, G. A. Chem. Rev. 1965, 65, 177-198.

[49]. Villaescusa, I.; Martinez, M.; Miralles, N. J. Chem. Technol. Biotechnol. 2000, 75, 812-816.

[50]. Low, K. S.; Lee, C. K.; Leo, A. C. Bioresour. Technol. 1995, 51, 227-231.

[51]. Mohan, D.; Singh, K. P.; Singh, G.; Kumar, K. Ind. Eng. Chem. Res. 2002, 41,3688-3695.

[52]. Bekci, Z.; Seki, Y.; Yurdakoc, M. K. J. Hazard. Mater. 2006, 133, 233242.

[53]. Suzuki, M. Adsorption Engineering, Kodansha/Elsevier, Tokyo, 1990.

[54]. Altundogan, H. S.; Altundogan, S.; Tumen, F.; Bildik, M. Waste Manage. 2000, 20, 761-767.

[55]. Genc-Fuhrman, H.; Tjell, J. C.; Mcconchie, D. Environ. Sci. Technol. 2004, 38, 2428-2434. 